\title{
Evaluation of double network hydrogel of poloxamer-heparin/gellan gum for bone marrow stem cells delivery carrier
}

\author{
Joo Hee Choi ${ }^{\mathrm{a}, 1}$, Ok Kyun Choi ${ }^{\mathrm{a}}$, Jeonghun Lee ${ }^{\mathrm{a}}$, Joungyoun Noh ${ }^{\mathrm{a}}$, Sumi Lee ${ }^{\mathrm{a}}$, Ain Park ${ }^{\mathrm{a}}$, \\ Min A. Rim ${ }^{\mathrm{a}}$, Rui L. Reis ${ }^{\mathrm{b}}$, Gilson Khang ${ }^{\mathrm{a} \text {, }}$ \\ a Department of BIN Convergence Technology, Department of Polymer Nano Science \& Technology and Polymer BIN Research Center, Chonbuk National University, \\ Deokjin-gu, Jeonju-si, Jeollabuk-do, 54896, Republic of Korea \\ ${ }^{\mathrm{b}}$ University of Minho - 3B's Research Group, AvePark Zona Industrial da Gandra, S. Cláudio do Barco, Guimarães, PT 4806-909, Portugal
}

\section{A R T I C L E I N F O}

\section{Keywords:}

Hydrogel

Bone marrow stem cells

Nature-derived

Synthetic

Double network hydrogel

Regeneration

\begin{abstract}
A B S T R A C T
In this study, a double network hydrogel of a natural polysaccharide gellan gum (GG) hydrogel and a synthetic hydrogel poloxamer-heparin $(\mathrm{PoH})$ hydrogel $(\mathrm{PoH} / \mathrm{GG} \mathrm{DNH})$ is introduced to complement disadvantages of each hydrogel and improve the microenvironment for cell delivery. The microstructure, surface morphology, gelation temperature, swelling and weight loss, sol fraction, mechanical property and thermal stability was examined. The potential of the composite hydrogel for cell vehicle was demonstrated by encapsulation of bone marrow stem cells isolated from rabbits (rBMSCs) within the PoH/GG DNH in vitro. The results showed that the DNH system supported cell survival and retained rBMSCs morphology and phenotype. Moreover, cell distribution, adherence, and ECM production were supported by PoH/GG DNH in vivo. Overall results provide a potential opportunity to apply the composite hydrogels in tissue engineering purpose.
\end{abstract}

\section{Introduction}

Stem cell transplantation plays a crucial role in regenerative medicine and tissue engineering. Especially, mesenchymal stem cells (MSCs) are multipotent and possess high self-renewal capacity and applying them can avoid ethical concerns. MSCs can differentiate into various cells such as osteoblasts, chondrocytes, adipocytes, endothelial cells, nerve cells, etc $[1,2]$. The applications of MSCs in tissue engineering strongly rely on the regulation of cell fate, cell morphology, proliferation, differentiation, and adhesion [3]. However, considerable cell death occurs after injection because of inflammation and deficiency of matrix support. A suitable vehicle for cell delivery is required to retain the appropriate amount of cells and preserve cell phenotype [4]. A matrix that mimics the native environment for cells growth, differentiation and regeneration are challenging. Among many studies, hydrogels are regarded as an appealing biomaterial due to their similarity to the extracellular matrix (ECM), high water content, porosity, biocompatibility, and biodegradability [5,6]. Hydrogels have the nature of being injectable which allow uniform distribution of cells and easily shape into defect model, potentially avoiding an open surgery with least invasive approaches $[7,8]$.

Recently, an interest of gellan gum (GG) has been generated due to its various advantages in pharmaceutical and biomedical applications $[9,10]$. GG hydrogel can transform from a coiled form to a double-helix structure when exposed to high $\left({ }^{\circ} 90^{\circ} \mathrm{C}\right.$ for a $1 \%$ solution) to low temperature [10]. This property provides soft and elastic gels to hard and rigid gels depending on the amount of GG. The presence of divalent cations such as $\mathrm{Ca}^{2+}$ and $\mathrm{Mg}^{2+}$ in GG hydrogel promotes a stable hydrogel structure for an injectable purpose [11]. GG hydrogel is easy to fabricate and can modify its mechanical and physical properties by changing the concentration of GG and a crosslinking agent [12-14]. In addition, GG hydrogel is studied to be biocompatible, low cytotoxicity and biodegradable [4].

Despite its many advantages in tissue engineering, GG hydrogel fails to meet the conditions of cell vehicle because of its too high gelation temperature for cell encapsulation. Another challenge which limits the application of GG hydrogel is lack of moieties for ligand binding [10]. Several reports lowered gelation temperature of GG hydrogel by chemically scissoring or carboxymethylation and thiolation of the backbone of GG hydrogel. A biological performance was enhanced modifying GG hydrogel into new derivatives [12,13,15-18]. There are also studies of GG hydrogel combined with other types of hydrogels such as hyaluronic acid, alginate, gelatin and polyethylene glycol (PEG) to tune the physicochemical properties [19-27].

\footnotetext{
* Corresponding author.

E-mail addresses: zooheechoi@jbnu.ac.kr (J.H. Choi), gskhang@jbnu.ac.kr (G. Khang).

${ }^{1}$ First author.
} 
Herein, a double network hydrogel (DNH) of GG hydrogel and synthetic hydrogel was developed to enhance biomechanical and physicochemical properties [25,28]. Poloxamer is an FDA approved hydrogel which is composed of hydrophobic poly (propylene oxide) (PPO) and hydrophilic poly (ethylene oxide) (PEO) [29-31]. Poloxamer hydrogel is proved to be effective in cell viability, non-toxicity, and biocompatibility. These properties are due to a highly lipophilic property of poloxamer hydrogel which mimics natural ECM and therefore enhances cell growth and communication [32,33]. Applications of poloxamer in cell delivery and improving its property are being actively studied [34-36]. Especially, heparin loaded poloxamer is proved to be effective in vitro and in vivo [37-42]. Although these studies report the effectiveness in the nerve system, it was considered that poloxamer loaded with heparin would be effective in MSCs because heparin is known to provide an improved surface for adhesion and proliferation $[43,44]$.

The effect of Poloxamer-heparin/gellan gum double network hydrogel (PoH/GG DNH) in chemical, mechanical and physical properties were evaluated. NMR and FTIR were studied to analyze a chemical structure. Rheological and TGA study was conducted to examine gelation temperature and thermal stability. SEM, swelling ratio, weight loss, sol fraction, and compression test were carried out to study the effects of the varying ratio of $\mathrm{PoH}$. Furthermore, the potential application of PoH/GG DNH in tissue engineering was verified by encapsulation of bone marrow stem cells (BMSCs). The in vitro studies were performed by SEM, MTT, live/dead assay, and dsDNA content. In addition, osteogenesis of encapsulated BMSCs was measured by ALP activity and mRNA expression analysis. A histological study was also analyzed to study the distribution and protein expression of cells. A preliminary in vivo study is also reported in this study to confirm biocompatibility and immune response of the hydrogels.

\section{Materials and methods}

\subsection{Preparation of poloxamer-heparin $(\mathrm{PoH})$ copolymer}

Poloxamer 407 was purchased in BASF, Ludwigshafen, Germany, SnakeSkin Dyalysis Tubing 3500 MWCO was supplied from Thermo Fisher Scientific, Waltham, MA, USA, dialysis tubing of 14,000 MWCO was purchased from Viskase, Willowbrook, IL, USA and rest of the materials were purchased from Sigma-Aldrich, St. Louis, MO, USA.

The synthesis of $\mathrm{PoH}$ copolymer has proceeded following an established procedure [33]. First, mono amine-terminated poloxamer (MAP) was prepared by dissolving $1.3 \mathrm{mM}$ 4-nitrophenyl chloroformate and $1 \mathrm{mM}$ poloxamer 407 in methylene chloride in the presence of trimethylamine at room temperature for $4 \mathrm{~h}$. The intermediate was obtained by using petroleum ether as an extract solution. The extraction was carried on 3 times. $1 \mathrm{mM}$ of intermediate and $3 \mathrm{mM}$ of diaminoethylene were dissolved in methylene chloride at room temperature for $48 \mathrm{~h}$. The product was extracted with petroleum ether 3 times. After extraction, the product was dialyzed in a dialysis tube $($ MWCO $=3000$ ) in distilled water for 3 days at room temperature and was lyophilized to gain MAP. The amine reaction between low molecular weight heparin from porcine intestinal mucosa and MAP was performed following the 1-ethyl-3-(3-dimethylaminoprophyl) carbodiimide hydrochloride (EDC)/ $N$-Hydroxysuccinimide (NHS) method to make PoH copolymer. $0.5 \mathrm{mM}$ MAP and $0.5 \mathrm{mM}$ heparin were reacted with $0.5 \mathrm{mM}$ EDC and $0.25 \mathrm{mM}$ NHS in $0.5 \mathrm{M} 2$-( $N$-Morpholino) ethanesulfonic acid hydrate (MES) buffer which was optimized to $\mathrm{pH}$ 5.6. The product was dialyzed in distilled water using a dialysis bag (MWCO $=14,000)$ for 3 days and lyophilized to acquire white powder of $\mathrm{PoH}$ copolymer. The chemical structure was studied by ${ }^{1} \mathrm{H}$ NMR (JEOL, JNM, $400 \mathrm{MHz}, \mathrm{CDCl}_{3}$ ) and Fourier transform infrared (FTIR, Perkin Elmer, USA) spectroscopy.

\subsection{Fabrication of poloxamer-heparin/gellan gum double network hydrogel (PoH/GG DNH)}

Gelzan powder (Sigma-Aldrich, St. Louis, MO, USA) was heated and stirred in a $90^{\circ} \mathrm{C}$ deionized water $1 \%(\mathrm{w} / \mathrm{v})$. $\mathrm{PoH}$ in variations of $0,0.1$, $0.5,1 \%(\mathrm{w} / \mathrm{v})$ were blended with GG (G1, P0.1-G1, P0.5-G1, P1-G1) and gently stirred for $4 \mathrm{~h}$. The DNH was crosslinked with $0.03 \%$ of $\mathrm{CaCl}_{2}$ to make a stable hydrogel. Hydrogels transferred on to a $6 \mathrm{~mm}$ diameter and $3 \mathrm{~mm}$ thickness silicon mold for gelation. The amount of $\mathrm{Ca}^{2+}$ in hydrogels was measured by inductively coupled plasma mass spectrometry (ICP-MS, 7500a, Agilent, USA).

\subsection{Characterization of $\mathrm{PoH} / G \mathrm{G} D \mathrm{DH}$}

\subsubsection{Swelling ratio}

Swelling ratio was acquired by following the conventional gravimetric method. Hydrogels were lyophilized and dry weight of the hydrogels was recorded. Hydrogels were immersed in PBS (pH 7.4, $\left.37^{\circ} \mathrm{C}\right)$ and measured the rehydrated weight (Wr) after specific time points. Swelling ratio was determined by the equations of (1) [45].

Swelling ratio $(\%)=(\mathrm{Wr}-\mathrm{Wi}) / \mathrm{Wi} \times 100 \%$

\subsubsection{Weight loss}

The hydrogels were placed in a 24-well plate with $1 \mathrm{~mL}$ of DPBS. At the specific time points, the solution was removed and all the hydrogels were washed with distilled water 3 times, lyophilized and weighed. The initial dry weight of hydrogels $\left(\mathrm{W}_{0}\right)$ and the dry weight after different time points $(\mathrm{Wt})$ were recorded. The weight loss of the gels was calculated using the equation of (2) [46].

Weight loss $(\%)=\left(\mathrm{W}_{0}-\mathrm{Wt}\right) / \mathrm{W}_{0} \times 100 \%$

\subsubsection{Sol fraction}

Sol fraction was evaluated by measuring the weight of dried hydrogels before (mi) and after (mf) immersion in distilled water with agitation for $1 \mathrm{~h}$. The sol fraction was calculated by following the equation of (3) [47].

Sol fraction $(\%)=(\mathrm{mi}-\mathrm{mf}) / \mathrm{mi} \times 100 \%$

\subsubsection{Morphological analysis}

Morphology of the hydrogels was confirmed by Bio-LV scanning electron microscope (SEM, Japan, HITACHI). The hydrogels were frozen at $4{ }^{\circ} \mathrm{C},-20^{\circ} \mathrm{C}$ and $-80^{\circ} \mathrm{C}$ for $3 \mathrm{~h}$ respectively followed by lyophilization overnight. The samples were cross-sectioned and gold sputtered for the observation.

\subsubsection{Thermal characterization}

All the hydrogels were lyophilized for thermal characterization. A Thermogravimetric analyzer (SDT, Q600, TA Instruments, South Korea) was used under $\mathrm{N}_{2}$ atmosphere at a heating rate of $10^{\circ} \mathrm{C} / \mathrm{min}$.

\subsubsection{Rheological evaluation}

The viscosity of GG hydrogel and PoH/GG hydrogel was determined to characterize gelation temperature and storage modulus. The viscometer (AMETEK Brookfield, Middleboro, MA, USA) was preheated before characterization. The solution was prepared and $10 \mathrm{~mL}$ of each sample was transferred to the viscometer. Viscosity was measured at various temperature intervals starting from high temperature. The router speed was set at $0.6 \mathrm{rpm}$ and the measurement was tested 3 times.

\subsubsection{Compressive strength}

The compressive strength was analyzed using a Texture Analyzed 
(FTC, Sterting, Virginia, USA). The samples with dimensions of $6 \mathrm{~mm}$ diameter and $4 \mathrm{~mm}$ height were prepared for the test. The hydrogels were incubated in $37^{\circ} \mathrm{C}$ for $24 \mathrm{~h}$ to analyze the equilibrium state (fully swollen). The compressive stress-strain curve was obtained by loading $10 \mathrm{~N}$ cells at the rate of $2 \mathrm{~mm} / \mathrm{min}$ in an unconfined condition and measured until the hydrogels reached $50 \%$ strain. A third order polynomial equation of stress-strain curves was created by using Prism 5.0 software (GraphPad Software, La Jolla, CA, USA. The compressive tangent modulus at $25 \%$ strain was calculated from the equation from the curve.

\subsection{In vitro study}

\subsubsection{Animal experiment}

All the animal experiments were performed in accordance with the guidelines and approval of Chonbuk National University Animal Care Committee, Jeonju, Republic of Korea (CBNU 2016-50). The surgery has proceeded under general anesthesia, and all attempts were made to minimize animal suffering.

2.4.2. Isolation and culture of bone marrow stem cells from a rabbit model

Rabbit bone marrow stem cells (rBMSCs) were cultured in Alpha Modified Eagle Medium (Alpha MEM, Gibco, Big Cabin, OK, USA) supplemented with $10 \%$ fetal bovine serum (FBS, Gibco, USA) and $1 \%$ penicillin/streptomycin (PS, Gibco, USA) under standard culture conditions $\left(5 \% \mathrm{CO}_{2}\right.$ and $\left.37{ }^{\circ} \mathrm{C}\right)$. rBMSCs were isolated from a 4 weeks old, female, New Zealand white rabbits (Hanil laboratory animal center, Wanju, Korea). Legs were removed from rabbits to obtain rBMSCs. The flesh was separated from the leg and the bone was washed 3 times with phosphate-buffered saline (PBS). Cartilage parts were snipped off with a scissor. rBMSCs were cultured on a cell culture dish for $3 \mathrm{~h}$ at $37^{\circ} \mathrm{C}$ with a humidified 5\% CO2 incubator (Step0). After $3 \mathrm{~h}$, supernatants were transferred to other cell culture dish using a cell strainer (Step1). After 3 days of culture, the culture medium was changed and on 5 days of culture, rBMSCs were washed with $2 \%$ PS. The medium was changed every 3 days and primary passage 2 of rBMSCs were used for this study.

\subsubsection{Cell encapsulation in $\mathrm{PoH} / \mathrm{GG} D \mathrm{DH}$}

All materials were sterilized by autoclave before seeding cells in PoH/GG DNH. The hydrogels in a vial were immersed in $37-42{ }^{\circ} \mathrm{C}$ water bath. $2 \times 10^{6}$ cells $/ \mathrm{mL}$ of BMSCs were used in this study. Hydrogels were co-cultured with rBMSCs in the temperature before the gelation occurred for homogeneous suspension of cells. More specifically, as shown in Section 3.4, chondrocytes were encapsulated in G1 at the temperature of $42{ }^{\circ} \mathrm{C}$, and at $37^{\circ} \mathrm{C}$ for P0.5-G1 and P1-G1. The hydrogels were cultured in an alpha-MEM media and the media was changed every 3 days. The morphology of cell encapsulation and adhesion was measured by Bio-LV SEM. The hydrogels were cultured for 3,7 and 14 days for characterization. On a specific time point, the samples were washed with PBS 3 times and fixed with $2.5 \%$ glutaraldehyde (Sigma-Aldrich, USA) for $24 \mathrm{~h}$ at $4{ }^{\circ} \mathrm{C}$. The glutaraldehyde was removed and the samples for Bio-LV SEM were acquired following the above method.

\subsubsection{Cell viability and cytotoxicity}

Cell viability and metabolic activity were measured using an MTT (3-[4,-dimethylthiazol-2-yl]-2,5-diphenylterazolium bromide; thiazolyl blue, Amresco, TX, USA) assay and were assessed after 1, 7 and 14 days of culture. Each sample was changed with a fresh medium and $100 \mu \mathrm{L}$ MTT solution ( $5 \mathrm{mg} / \mathrm{mL}$ in PBS) was added. Hydrogels were incubated for $3 \mathrm{~h}$ under standard culture conditions $\left(5 \% \mathrm{CO}_{2}\right.$ and $\left.37^{\circ} \mathrm{C}\right)$ to form a formazan crystal. The supernatant was removed after incubation and $1 \mathrm{~mL}$ of DMSO was added to dissolve formazan crystal. The solution was transferred into 96-well plate and measured at an absorbance of $570 \mathrm{~nm}$ using a microplate reader (Synergy MX, Biotek, Vernusky, VT, USA). Further cell viability and cytotoxicity were measured by a live/dead assay. A live/dead cell imaging kit (Invitrogen, Carlsbad, CA, USA) was applied following the kit protocol. Live/dead cell images were measured with a confocal Z-stack by using Super Resolution Confocal Laser Scanning Microscope (LSM 880 with Airyscan, Carl Zeiss, Germany) installed in the Center for University-Wide Research Facilities (CURF) at Chonbuk National University. Live cells were stained with calcein AM (green) and the dead cells were stained with ethidium homodimer (red).

\subsubsection{Double-stranded DNA content and ALP analysis}

The double-stranded DNA was quantified by using a Quant-IT PicoGreen dsDNA quantification kit (Life Technologies, Carlsbad, CA, USA). On 1, 7 and 14 days of culture, hydrogels were washed with PBS 3 times and stored at $-80^{\circ} \mathrm{C}$ for further analysis. All the samples were thawed at room temperature and each hydrogel was homogenized in $1 \mathrm{~mL}$ of MES buffer with a glass tissue grinder (WHEATON, USA) to induce complete membrane lysis. For further lysis, samples were vortexed vigorously. $100 \mu \mathrm{L}$ of samples were transferred into black 96-well plates and $100 \mu \mathrm{L}$ of Quanti-iT PicoGreen reagent was added. The plate was incubated in room temperature for $3 \mathrm{~min}$. A microplate reader was set as an excitation wavelength of $485 / 20 \mathrm{~nm}$ and an emission wavelength of $528 / 20 \mathrm{~nm}$. Concentrations which range from 0 to $1 \mu \mathrm{g} / \mathrm{mL}$ was used as a standard curve to quantify DNA content. Furthermore, ALP activity was studied by using the ALP assay kit (Takara Bio, Japan). The rBMSCs were cultured in the hydrogels for 1, 7, 14 days. All the samples were washed with PBS 3 times and stored at $-80{ }^{\circ} \mathrm{C}$ at the specific time. The hydrogels were homogenized in $1 \mathrm{~mL}$ extraction solution with a glass tissue grinder to extract the cultured rBMSCs and $50 \mu \mathrm{L}$ of p-nitrophenyl phosphate (pNPP) was added into each sample in a dark room and incubated in a humidified $5 \% \mathrm{CO}_{2}$ incubator for $1 \mathrm{~h}$. The reaction was stopped with $50 \mu \mathrm{L}$ of $0.9 \mathrm{~N} \mathrm{NaOH}$ and measured with a microplate reader at an absorbance of $405 \mathrm{~nm}$.

\subsubsection{Quantitative real-time polymerase chain reaction ( $q R T-P C R$ )}

BMSCs of $2 \times 10^{6}$ cells $/ \mathrm{mL}$ were seeded in each hydrogel and cultured in alpha-MEM for 14 days for RT-PCR. Samples were washed with PBS 3 times. Cells were extracted from the hydrogels by using a glass tissue grinder. Trizol (Invitrogen, USA) and Chloroform (Sigma-Aldrich, USA) were used for cell lysis and centrifuged at $12,000 \mathrm{~g}$ in $4{ }^{\circ} \mathrm{C}$ for $15 \mathrm{~min}$. The supernatant was removed and transferred to a $1.5 \mathrm{~mL}$ Eppendorf tube. Further RNA was extracted using an RNeasy Mini Kit (QIAGEN, Hilden, Germany). cDNA samples were prepared by performing a reverse transcription reaction using a cDNA Synthesis kit (Biorad, CA, USA). qRT-PCR was conducted by StepOnePlus Real-Time PCR system (Applied Biosystems, USA). The Collagen type I (COL1), Osteocalcin (OCN), Runt-related transcription factor 2 (RUNX-2) were used for the expression of osteogenic markers.

\subsubsection{Histological analysis}

Hydrogels were seeded with $2 \times 10^{6}$ cells/mL BMSCs and cultured in alpha-MEM for 7 and 14 days for histological analysis. Samples were fixed with $4 \%$ formaldehyde for $15 \mathrm{~min}$. The hydrogels were placed in a CryoMatrix (Thermo Fisher Scientific, USA) and frozen by liquid nitrogen. The samples were sectioned with a cryomicrotome (Thermo Fisher Scientific, USA) at $10 \mu \mathrm{m}$ thickness and placed on microscope slides. The slides were stored in $-20{ }^{\circ} \mathrm{C}$ until usage. Hematoxylin\& Eosin (H\&E, Fisher Scientific, Hampton, USA) staining was proceeded to determine the morphology of cells. The sectioned samples were rehydrated and washed with PBS several times. The slides were treated with hematoxylin for $5 \mathrm{~min}$ and eosin for $30 \mathrm{~s}$. Furthermore, immunofluorescence staining was proceeded by blocking a nonspecific bonding by using a protein blocking solution (DAKO, Glostrup, Denmark) for $12 \mathrm{~min}$ in a dark room at room temperature. After washing for several times, the slides were incubated with E-cadherin (Santa Cruz Biotechnology, Dallas, TX, USA) and Laminin (Invitrogen, USA) primary antibody in a dark room at $4{ }^{\circ} \mathrm{C}$ for overnight. The slides were 
then stained with Alexa Fluor ${ }^{\mathrm{TM}} 488$ goat anti-rabbit $\operatorname{IgG}(\mathrm{H}+\mathrm{L})$ (Invitrogen, USA) and Alexa Fluor ${ }^{\mathrm{TM}} 594$ donkey anti-rabbit IgG $(\mathrm{H}+\mathrm{L}$ ) (Invitrogen, USA) secondary antibody. A mounting medium DAPI (Santa Cruz Biotechnology, USA) was used to stain the DNA of all the samples. The immunofluorescence images were taken by a Super Resolution Confocal Laser Scanning Microscope.

\subsection{In vivo study}

\subsubsection{Implantation of the hydrogels}

G1 and G1-PoH0.5 were chosen for the in vivo study. The hydrogels were seeded with $2 \times 10^{6}$ cells/mL of BMSCs and cultured for 3 days in Alpha MEM media. 6 weeks old nude athymic mice (OrientBio, Seongnam, South Korea) were used in this study. All the mice were anesthetized intramuscularly by injecting $0.05 \mathrm{cc}$ of 9:1 ratio of Alfaxalone $(10 \mathrm{mg} / \mathrm{mL}$, Jurox, Rutherford, Australia) and Dormitor ( $1 \mathrm{mg} / \mathrm{mL}$, Orion Pharma, Espoo, Finland). The seeded hydrogels were implanted under the dorsal subcutaneous region of the nude mice.

\subsubsection{Histological studies}

All animal experimental procedures were performed with the approval of the Chonbuk National University Animal Care Committee, Jeonju, South Korea. The mice were sacrificed on 1, 3, and 6 weeks and hydrogels were removed with the surrounding tissues. The samples were fixed by using $4 \%$ formaldehyde for $48 \mathrm{~h}$. The hydrogels were frozen with CryoMatrix in liquid nitrogen for cryosection. All the samples were sectioned at $10 \mu \mathrm{m}$ thickness. H\&E staining was performed by following standard histological techniques. Immunoperoxidase staining was performed to verify the inflammatory response. CD68 antibody (ED1, Santa Cruz Biotechnology, USA) was used for the staining by following the product protocol. Briefly, slide glasses were washed with PBS 3 times and quenched endogenous peroxidase activity by incubating with $1 \%$ hydrogen peroxide. The specimens were incubated with blocking reagent to prevent nonspecific binding for $1 \mathrm{~h}$ in room temperature. The $8 \mu \mathrm{g} / \mathrm{mL}$ primary antibody was diluted in blocking reagent and incubated the samples with primary antibody at $4{ }^{\circ} \mathrm{C}$ for overnight. The samples were incubated with HRP-conjugated mouse IgG kappa binding protein (m-IgG $\mathrm{I}_{\mathrm{K}}$ BP-HRP, Santa Cruz Biotechnology, USA) which was diluted in blocking reagent with the ratio of $1: 25$ for $90 \mathrm{~min}$ at room temperature and washed with PBS for 2 times. The slides were stained with 3-amino-9-ethylcarbazole (AEC) chromogen kit (Sigma-Aldrich, USA) for $20 \mathrm{~min}$ at room temperature. The sections were washed in deionized $\mathrm{H}_{2} \mathrm{O}$ and dehydrated with $90 \%$ ethanol and $100 \%$ ethanol.

\subsection{Statistics}

All the numerical results are presented by the mean \pm standard deviation (SD). The GraphPad Prism 5.0 software (GraphPad Software, La Jolla, CA, USA) was utilized to perform the statistical analysis. The mechanical properties and in vitro studies were analyzed by means of one-way analysis of variance (one-way ANOVA test), and the differences were considered significant at $\mathrm{P}<0.05\left(^{*}\right), \mathrm{P}<0.01\left(^{* *}\right)$, and $\mathrm{P}<0.001(* * *)$.

\section{Results}

\subsection{Synthesis of PoH copolymer}

The synthesis route of $\mathrm{PoH}$ is shown in the Supplementary data 1A. The chemical structure of $\mathrm{PoH}$ was determined by ${ }^{1} \mathrm{H}$ NMR and FTIR. The characteristic peak appeared at $\mathrm{d}=1,2.7 \mathrm{ppm}$ in heparin and $\mathrm{d}=1,2.7,3.5 \mathrm{ppm}$ in Poloxamer. The $\mathrm{PoH}$ displayed resonance signals of $\mathrm{d}=1,2.5,3.3,3.5 \mathrm{ppm}$ which refers that PoH copolymer was successfully synthesized (Supplementary data 1B). The FTIR data showed characteristic absorption peak of $\mathrm{PoH}$ at $3665-3152 \mathrm{~cm}^{-1}$ and
$1630 \mathrm{~cm}^{-1}$ (a), (c) from heparin and $3005-2785 \mathrm{~cm}^{-1}$ (b) from poloxamer characteristic peak. A new absorption peak at $1735-1115 \mathrm{~cm}^{-1}$ (d) wavelength, which belonged to carbonyl vibration of $\mathrm{PoH}$ complex was observed (Supplementary data 1C) [39]. Moreover, FTIR data of hydrogels exhibited significant peak at the range of (a) $3000-3650 \mathrm{~cm}^{-1}, \quad$ (b) $2865-2900 \mathrm{~cm}^{-1}, \quad$ (c) $1695-1530 \mathrm{~cm}^{-1}$ and (d)1160-960 $\mathrm{cm}^{-1}$ (Supplementary data 1D). The PoH characteristic molecular composition was near G1, therefore, new peak did not appear in the PoH/GG DNH. However, as the PoH content elevated, infrared induced stretching in the range of (d) in P1G1 began to divide into two peaks similar to $\mathrm{PoH}$.

\subsection{Thermal stability}

The SDT was proceeded to confirm thermal stability and characters of hydrogels. The PoH and G1 displayed two main weight loss; PoH: 4\%, 89.21\%; G1: 12.13\%, 62.66\%. The PoH/GG DNH showed 3 main weight loss: P0.1-G1: 12.75\%, 51.25\%, 18.52\%; P0.5-G1: 9.319\%, 42.12\%, 32.90\%; P1-G1: 7.549\%, 32.50\%, 48.65\% (Supplementary data 2). The weight loss of PoH/GG DNH decreased in the first and second step and increased in the last step as the content of PoH increased. The first step of the weight loss in all hydrogels is due to the loss of water, the second step and third step are attributed to the thermal degradation of polymers [48]. The second step weight loss of PoH/GG DNH is due to the degradation of GG hydrogel, while the third step is because of the decomposition of $\mathrm{PoH}$.

\subsection{Internal structure characterization of $P o H / G G D N H$}

To analyze the microstructure of hydrogels, PoH, G1 and PoH/GG DNH of different proportion were investigated under SEM. The crosssectional SEM images presented a continuous porous structure. The pores were produced by ice crystal formation because of the freezedrying step. The pore diameter $(\mu \mathrm{m})$ decreased as the PoH content increased; G1: $196.51 \pm 54.6 \mu \mathrm{m}$; P0.1-G1: $185.11 \pm 65.1 \mu \mathrm{m}$; P0.5-G1: $149.16 \pm 37.03 \mu \mathrm{m}$; P1-G1: $98.69 \pm 23.31 \mu \mathrm{m}$ (Fig. 1B). The surface morphology showed different properties. G1 exhibited lamellar structure while PoH/GG DNH exhibited rougher and wrinkled construction (Fig. 1A, supplementary data 3). For further observation, PoH concentration of $10 \%(\mathrm{w} / \mathrm{v})(\mathrm{P} 10)$ was studied. The P10 displayed piled structure and rough surface which contributed to the different morphology of PoH/GG DNH (supplementary data 3).

\subsection{Physicochemical characterization of $P o H / G G D N H$}

The kinetic of PoH/GG DNH with different formulation was measured by evaluating the viscosity (Pa s) as a function of temperature to monitor the gelation temperature of hydrogels. The transition from liquid-like behavior to elastic gel-like behavior revealed at approximately $\sim 2{ }^{\circ} \mathrm{C}, \sim 40{ }^{\circ} \mathrm{C},{ }^{\sim} 36^{\circ} \mathrm{C}$ and $\sim 35^{\circ} \mathrm{C}$ at G1, P0.1-G1, P0.5-G1 and P1G1 respectively (Fig. 2A). The sol-gel transition appeared as soon as the elastic gel-like behavior appeared and the storage modulus $\mathrm{G}^{\prime}(\mathrm{kPa})$ values were 2.54, 1.97, 1.57 and 1.43 in G1, P0.1-G1, P0.5-G1, and P1G1. Unlike other DNH, the resulting matrix did not display higher mechanical properties after gelation. This may be attributed to $\mathrm{PoH}$ interfering the crosslinking process of GG. The relative amount of $\mathrm{Ca}^{2+}$ a divalent cation which involves in crosslinking and mechanical characters was measured using ICP-MS. The confirmed data showed that the amount of $\mathrm{Ca} 2+$ decreased as the PoH was incorporated (Supplementary data 4). However, the compressive stress-strain curve of the hydrogels displayed interesting data. Although hydrogels displayed lower storage modulus after crosslinking process, the equilibrium state of the samples showed similar or higher compressive modulus when compared with G1. This indicates that the appropriate amount of PoH does not interfere the mechanical property in an equilibrium state of the hydrogels (Supplementary data 5). 
(A) G1 P0.1-G1 P0.5-G1 P1-G1

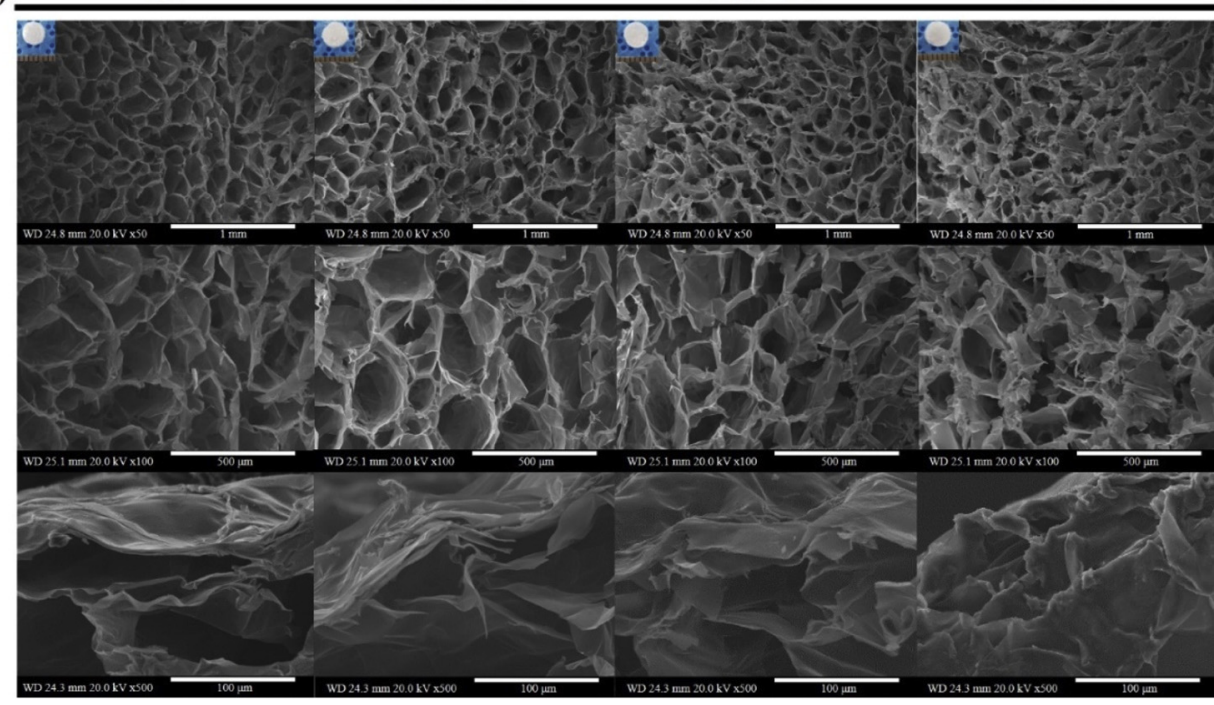

(B)

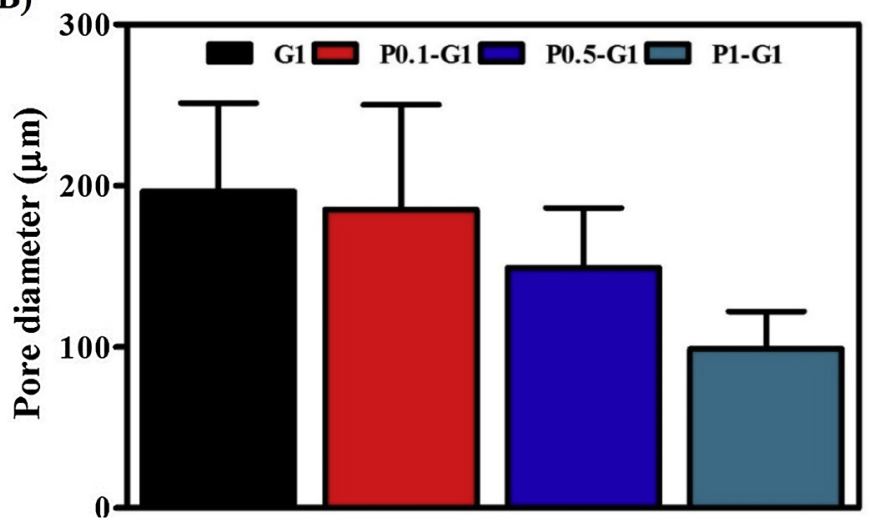

Fig. 1. (A) Morphological evaluation of GG hydrogel and PoH/GG DNH observed under SEM (B) pore diameter of lyophilized hydrogels (values are mean \pm SD $(n=3)$.

The swelling ratio which indicates water sorption capacity was characterized. G1 and P0.1-G1 displayed $5312.5 \pm 354.44 \%$ and $4790.78 \pm 603.7 \%$ while P0.5-G1 and P1-G1 had $3600 \pm 482.93 \%$ and $3400.722 \pm 809.17 \%$ (numbers are represented as mean $\pm \mathrm{SD}$ ) (Fig. 2B). The crosslinking density may be higher in G1 but the decrease of pore size and interconnected matrix reduced the swelling ratio of PoH/GG DNH. The amount of water penetration is studied to be connected to hydrogel degradation [49]. The sol fraction which shows the fraction of polymer that is not involved in a crosslinked network was characterized. The result displayed $35.18 \pm 8.93 \%$ in G1, $36.30 \pm 7.71 \%$ in P0.1-G1, $38.81 \pm 6.96 \%$ in P0.5-G1, and $41.36 \pm 16.75 \%$ in P1-G1 (numbers are represented as mean \pm SD) (Supplementary data 6). The fraction increased as the $\mathrm{PoH}$ increased which may be attributed to lower propagation of crosslinking in the hydrogels [47]. The weight loss was investigated for 35 days. The mass of hydrogels gradually decreased and the last day of the study showed the weight loss of $44.73 \pm 5.98 \%$ in G1, $47.92 \pm 14.43 \%$ in P0.1-G1, $51.95 \pm 9.73 \%$ in P0.5-G1, and $55.56 \pm 13.88 \%$ in P1-G1 (numbers are represented as mean \pm SD) (Supplementary data 7). The degradation was higher as $\mathrm{PoH}$ was incorporated which may be due to the lower crosslinking. However, lower swelling ratio and higher hydrophobic chain of $\mathrm{PoH}$ which decrease the exposure of water molecule may have delayed fast weight loss $[6,50]$.

\subsection{Morphology of cell incorporated DNH}

Cell encapsulated hydrogels were cultured for a specific time and were studied under SEM. The macro-porosity enabled cells to penetrate into the hydrogels. All the cells were well encapsulated in hydrogels and exhibited round shape. The high water content of hydrogel which performs similar environment to that of ECM may provide maintainable bioactivity to support cell survival. A significant difference between groups did not appear on 3 days but higher growth of cells was exhibited on 7 days in PoH/GG DNH. Moreover, on 14 days of culture, PoH/GG DNH displayed further adhered and spread cells on the surface (Fig. 3).

\subsection{Cell viability and cytotoxicity test}

The metabolic activity of rBMSCs in the hydrogels was analyzed at specific time point to observe cell viability. It was investigated that the metabolic activity increased in all hydrogels which may be due to the growth of cells. The P0.5-G1 showed the highest viability above all groups (Fig. 4A). Live/Dead analysis was carried out to test cell viability and cytotoxicity. The higher amount of cells appeared in all hydrogels because of cell proliferation. Roundly shaped rBMSCs were uniformly distributed. In order to uniformly disperse cells in hydrogels, rBMSCs were seeded in a liquid state (Materials and Methods 2.3.4). For 


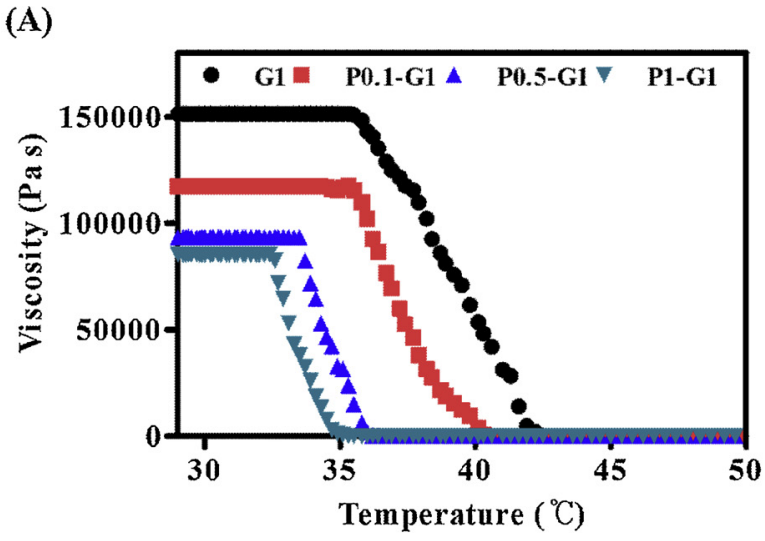

(B)

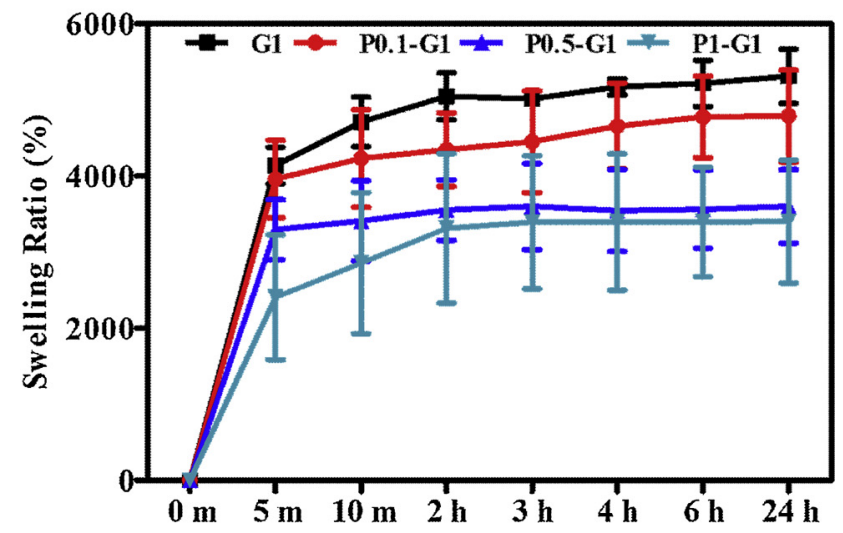

Fig. 2. (A) Viscosity of hydrogels (B) swelling ratio (\%) of hydrogels studied for $24 \mathrm{~h}$ in PBS at $37^{\circ} \mathrm{C}$ (values are mean $\pm \mathrm{SD}(\mathrm{n}=3)$ ).

this reason, many dead cells were observed on G1 on 1 day after seeding. PoH/GG DNH appeared higher viability compared to G1 and especially P0.5-G1 displayed the highest amount of live cells which appeared as the most appropriate formulation for cell culture material (Fig. 4B, supplementary data 8).

\subsection{Cell proliferation and ALP activity}

To test cell proliferation and osteogenic differentiation in cells, dsDNA content and ALP test were proceeded. A high amount of DNA was observed in P0.5-G1 at 14 days of culture (Fig. 5A). ALP activity did not display a distinction between groups on 1 day and 7 days of culture but difference exhibited on 14 days. The PoH/GG DNH showed higher ALP activity and especially P0.5-G1 was the highest (Fig. 5B).

\section{8. mRNA expression analysis}

The COL1, OCN, RUNX-2 which are osteogenesis specific markers were used to investigate mRNA expression in cell cultured hydrogels. Compared to G1, PoH/GG DNH expressed higher relative quantification (RQ): P0.5-G1 (2.26 fold), P1-G1 (1.06 fold) in OCN (Fig. 6A); P0.5-G1 (2.25 fold), P1-G1 (1.5 fold) in COL1 (Fig. 6B); P0.5-G1 (2.49 fold), P1G1 (1.9 fold) in RUNX-2 (Fig. 6C). The P0.5-G1 was observed to express the highest osteogenic differentiation markers.

\subsection{Histological studies}

H\&E staining was observed to study distribution across the depth of the hydrogels and construction of cells. All hydrogels displayed well dispersed and proliferated cells which indicate efficient encapsulation. Notably, P0.5-H1 showed more cells attached to each other on 14 days which increased cell to cell interaction (Supplementary data 9). Immunohistology staining was conducted to observe cell adhesion molecule and extracellular matrix (ECM) protein expression. E-cadherin expression was low in 7 days but on 14 days, P0.5-G1 expressed the highest intensity which may be due to the cell attachment that was exhibited in H\&E staining (Fig. 7A). The Laminin was highly expressed in PoH/GG DNH on 7 and 14 days because of the higher network between cells and hydrogels (Fig. 7B).

\subsection{In vivo study}

The H\&E staining figures show that the in vivo study was well performed. At 7 and 21 days, G1 was not attached to tissues whereas P0.5G1 was closely located to tissues. At 42 days, the tissue displayed penetration into the hydrogel (Fig. 8A). The ED1 staining was performed to examine the phagocytic activity of macrophages which appears at the inflammatory response. G1 showed aggregated macrophages in tissue while P0.5-G1 presented lower intensity of staining (Fig. 8B).

\section{Discussion}

Engineered hydrogels are considered as a promising material to provide an optimal environment to maintain long lasting cell viability of stem cells in situ $[19,51,52]$. These materials allow the cells to be delivered appropriately into the defect sites for the treatment purpose [5,52-54]. However, various limits in cell function and growth have been exhibited when stem cells are encapsulated into biomaterials $[2,5,6,57]$. Many attempts such as changing the mechanical properties, modifying the backbone of the polymer or incorporating biomolecule materials have been made to improve hydrogel design [5].

In this study, the double network of gellan gum (GG) hydrogel crosslinked with $\mathrm{Ca}^{2+}$ and poloxamer-heparin $(\mathrm{PoH})$ hydrogel is introduced in order to acquire systems with tissue engineering biomaterials potential. Despite that GG hydrogel has various merits, high gelation temperature for cell encapsulation, and lack of cell binding site is yet problems to be solved $[9,14,15,25,56,57,58,59]$. PoH hydrogel is studied to recapitulate features of the natural ECM which increases cell proliferation, differentiation and communication $[43,44]$. However, the poor mechanical performance and requirement of the high amount to fabricate hydrogel limit its application in biofabrication. The $\mathrm{PoH}$ and GG double network hydrogel (PoH/GG DNH) enabled hydrated 3D network with highly porous, mechanically stable hydrogel and proper mircroenvironment for cell culture.

The copolymer of PoH was well fabricated as shown in the ${ }^{1} \mathrm{H}$ NMR and FTIR (Supplementary data 1A, B) [39]. The PoH/GG DNH FTIR result demonstrated the combined characteristic major peaks of both GG and PoH hydrogel (Supplementary data 1C). The absence of further additional chemical group in PoH/GG DNH FTIR data confirmed that the interaction between PoH and GG were not intermolecular dependent in the DNH system. The intermolecular hydrogen bonding between polar bonds in PoH and GG have attributed to the different peaks between each group of hydrogels [60]. Thermal stability was confirmed by SDT analysis. Thermal stability and degradation are related to the microstructure of polymeric materials. Particularly, interactions of intra- and intermolecular interactions between the polymeric chains affect the thermal character [60]. The major weight loss of the hydrogel moved to a higher temperature as the $\mathrm{PoH}$ concentration increased in the PoH/GG DNH structure (Supplementary data 2). It is assumed that the entanglement between two macromolecular chains are stabilized by hydrogen bonding as the $\mathrm{PoH}$ is incorporated in higher concentration. A large number of pores are required for cell encapsulation to deliver oxygen, nutrients, proteins and for cells to migrate inside the microstructure $[1,3,29,31]$. It is reported that cell adhesion on surface decrease when the pore size highly increases. The range between 


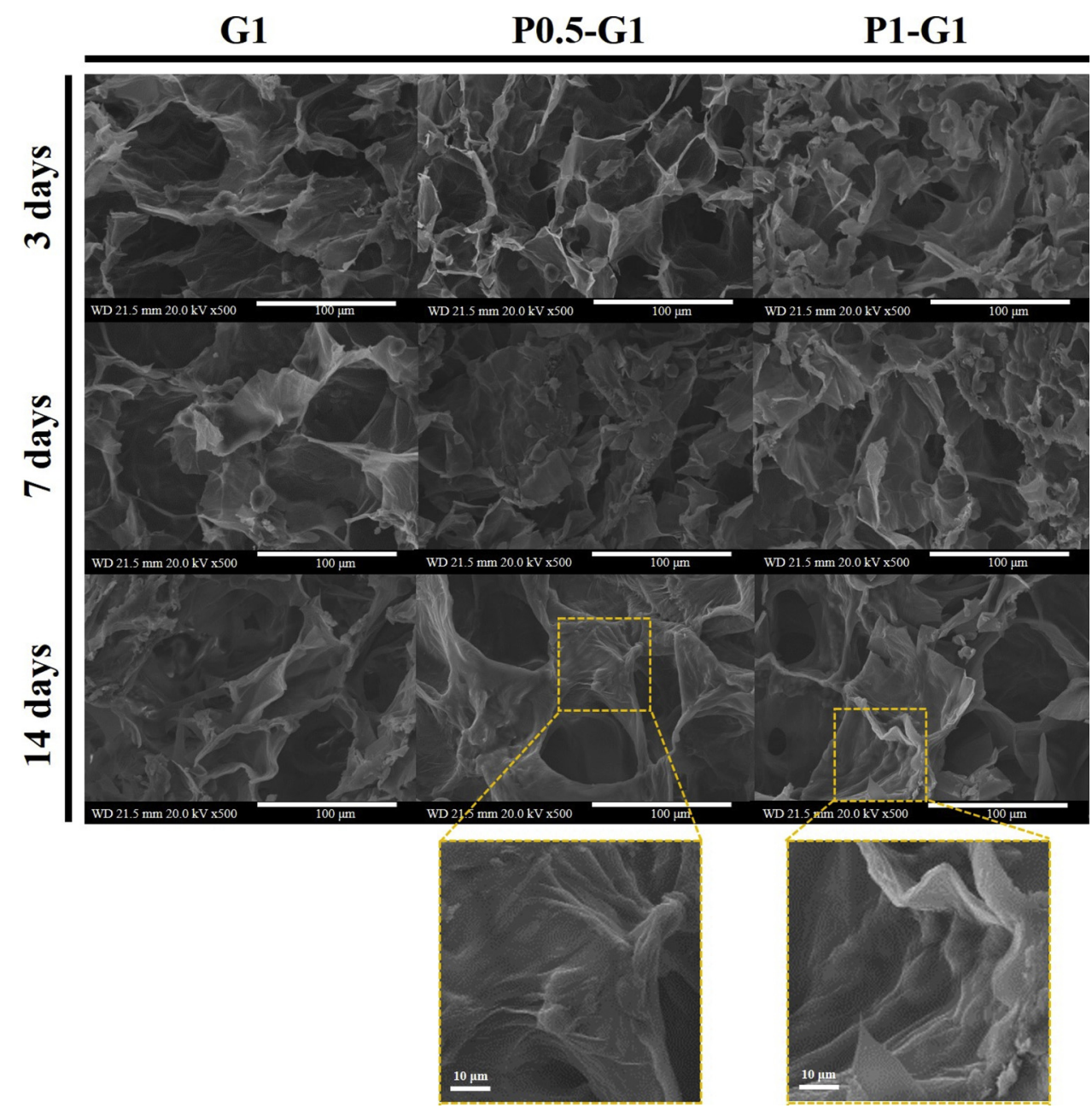

Fig. 3. Evaluation of encapsulated cells in hydrogels studied on 3, 7 and 14 days, images taken under SEM.

90-151 $\mu \mathrm{m}$ had linear dependence between pore size and cell adhesion $[60,61]$. The inner structure of the hydrogels displayed interconnected porous structure and the pore sizes decreased as the proportion of $\mathrm{PoH}$ increased (Fig. 1A, B). This may be due to the network of PoH hydrophobic moieties in the hydrogels and physical cross-linking of GG hydrogel [62]. The property of swelling ratio and weight loss also decreased as the $\mathrm{PoH}$ concentration increased (Fig. 2A, Supplementary data 6). The hydrophobic properties of $\mathrm{PoH}$ and complicated structure of macromolecular chains decreased the exposure of water molecule to the hydrogel matrix, and decreased water absorption [8]. The complicated structure of the PoH/GG DNH enhanced the degradation property. The compressive stress-strain curve of the hydrogels exhibited higher modulus compared to G1 (Supplementary data 5). The PoH/GG DNH displayed lower crosslinking agent in the hydrogel as shown in ICP-MS (Supplementary data 4) and higher sol fraction when the $\mathrm{PoH}$ content increased (Supplementary data 6) but exhibited a $10.83 \%$ difference in degradation when compared with G1 and P1-G1 (Supplementary data 7). This result signifies that PoH/GG DNH increased both the physical properties and microenvironment of the hydrogel. The gelling temperature of hydrogels also displays that PoH/GG DNH is proper material for cell vehicle. The presence of divalent cations allows GG hydrogel to undergo thermos-reversible gelation below gelation temperature and form a gel that is stable below melting temperature. However, the gelation temperature is too high for homogeneous cell encapsulation. The PoH/GG DNH displayed lower gelation temperature which allowed cell dispersion in $37^{\circ} \mathrm{C}$ physiological temperature for an injectable purpose (Fig. 2A) [9]. The decrease in gelling temperature is due to the lower crosslinking agent and complex network between two polymers which inhibited aggregation of GG hydrogel [14]. Compared to many attempts to decrease gelation temperature of GG hydrogel, PoH/GG DNH allowed easy processing of hydrogel.

The biological activity of rBMSCs was verified by in vitro studies. Encapsulation of cells was confirmed under SEM. The difference did not show on the 3 and 7 days which displayed the round shape of cells. However, PoH/GG DNH exhibited spindle-like morphology of cells (Fig. 3). Alteration of a round to a spindle-like figure represents healthy cells which support long-term survival [63]. The hydrogel microenvironment of the rough surface and complex network induced highly attached and stretched cells [64].

A cytocompatibility which is a crucial character for biomaterials to maintain cell survival of the materials was measured. The OD value of P0.5-G1 displayed highest compared to other groups which indicate that proper amount of PoH in GG hydrogel can enhance in vitro biocompatibility (Fig. 4A). Moreover, live/dead assay displayed higher dead cells on GG hydrogel which may be due to the seeding temperature which is too high for cell encapsulation. The PoH/GG DNH exhibited proliferated cells on 7 and 14 days compared to 1 day of culture (Fig. 4B, Supplementary data 8). In addition, dsDNA and ALP activity were analyzed for cell proliferation and osteogenic differentiation of rBMSCs. The dsDNA content result showed a similar aspect as the live/ dead assay. Higher cell proliferation was studied in P0.5-G1 compared to other groups (Fig. 5A). Furthermore, osteogenic differentiation did not present difference on 1 and 7 days which may be attributed to less attached cells, but PoH/GG DNH showed higher ALP activity on 14 days of cultivation (Fig. 5B). Also, on the 14 days of culture, the P0.5G1 displayed the highest mRNA expression of rBMSCs specific markers 
(A)

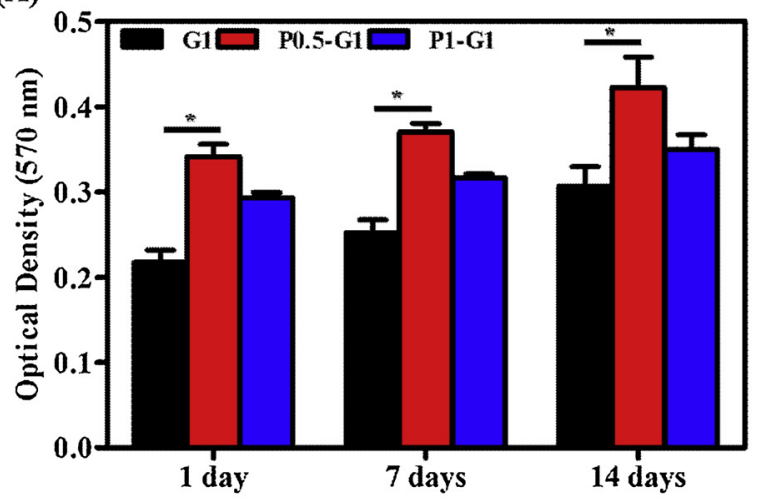

Fig. 4. MTT assay exhibited in OD values evaluated on 1, 7 and 14 days (values are mean \pm SD $\quad(n=3), \quad P<0.05\left(^{*}\right) \quad$ and $\mathrm{P}<0.01\left({ }^{* *}\right)$, relative to G1) (B) LSM images showing encapsulated rBMSCS in GG hydrogel and PoH/GG DNH. The live cells were stained with calcein AM (green), the dead cells were stained with ethidium homodimer (red) and were evaluated in Z-stack (scale bar $50 \mu \mathrm{m}$ ). (For interpretation of the references to colour in the text, the reader is referred to the web version of this article.)
(B)

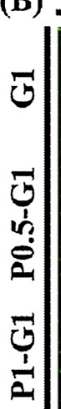

1 day

7 days

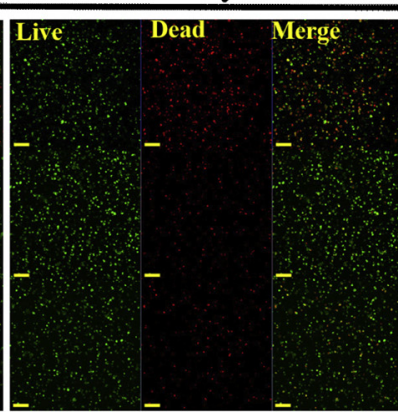

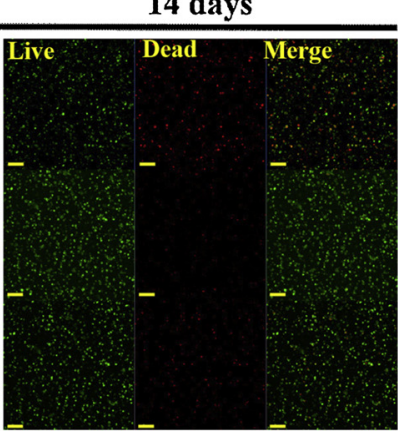

14 days
(Fig. 6). The stem cell growth and differentiation can be affected by mechanical properties, topography and chemical structures [37,55,65-67]. A proper microenvironment such as pore sizes, porous morphology, rough surface, cell cohesive site and lyophilic environment of PoH/GG DNH allowed higher cell adhesion, proliferation, and differentiation [37].

The histological analysis was studied to observe cell distribution and protein expression of cell junction specific and ECM component marker. The E-cadherin denote the cell to cell adhesion, while Laminin represents ECM specific marker which is potential for increasing the biological activities [68-70]. The P0.5-G1 displayed a great amount of cell adhesion and the expression of E-cadherin was high (Supplementary data 9, Fig. 7A). Moreover, the Laminin expression was higher in PoH/GG DNH compared to G1 (Fig. 7B). The component of the hydrogel network and the morphology of microenvironment have induced proper condition for cells to grow and interact with each other.

In vivo experiment confirmed the higher biocompatibility of $\mathrm{PoH} /$ GG DNH compared to the pristine GG. The morphology of attachment between tissue and hydrogel was higher in P0.5-G1. Furthermore, at 42 days of post-surgery, P0.5-G1 displayed infiltration of cells from surrounding tissues through the hydrogel which may be due to improved microenvironment and heparin ligand which increased the cell attachment and therefore enhanced bioadhesion and biocompatibiltily (Fig. 8A) [71]. In addition, biological activity in PoH/GG DNH was well developed by hydrogels and rBMSCs which improved the immune responses in vivo (Fig. 8B). The 7 days of post-implantation showed the highest amount of macrophage aggregation which may be due to the surgical method [72]. However, ED1 expression gradually decreased in both groups but G1 still displayed macrophage aggregation at 42 days of post-surgery. P0.5-G1 presented lower ED1 intensity as time passed because of the enhanced biological environment. Thus, the result of in vivo study implies that the PoH/GG DNH has acceptable biocompatibility and is suitable for in vivo purpose.

To sum up, complicated entanglement of macromolecular chains enabled stable morphological and physical properties which improved microenvironment for cell proliferation, ECM production, and maintenance of phenotype. As the process of PoH/GG DNH fabrication is simple, feasible and avoid toxic crosslinking processes such as using organic solvent or UV environment, such composite matrix will have potential application in tissue engineering. More interestingly, it is well known that the heparin-based materials can entrap and release various growth factors or ECM molecules [32,37,40,42-44]. The growth factors
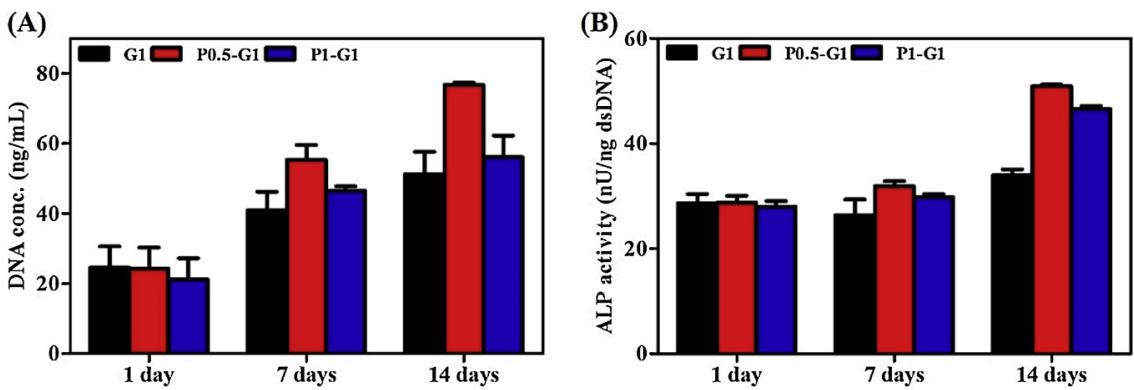

Fig. 5. (A) DNA quantification of the rBMSCs encapsulated in the hydrogels (B) ALP activity normalized by dsDNA content on 1, 14 and 14 days of cell culture (values are mean $\pm \mathrm{SD}$, $(\mathrm{n}=3)$ ). 
(A)

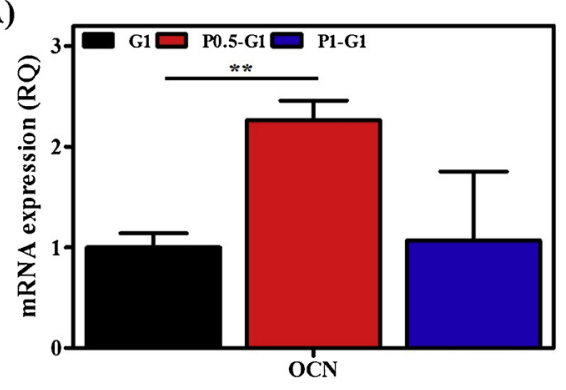

(B)

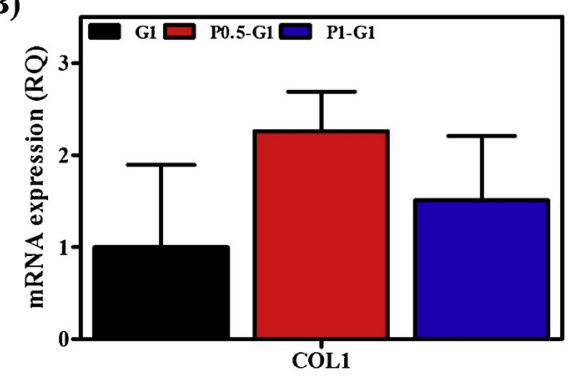

(C)

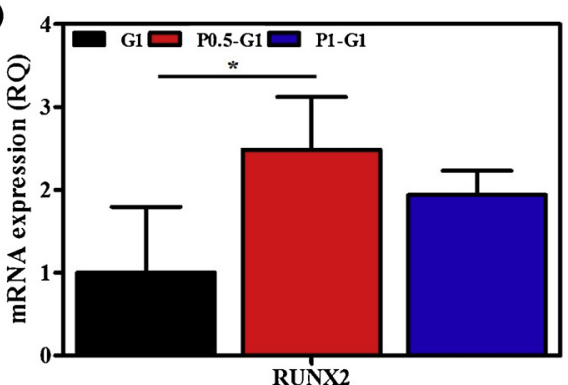

Fig. 6. Expression of bone-specific genes (A) osteocalcin (OCN), (B) collagen type I (COLI), and (C) runt-related transcription factor 2 (RUNX-2) of rBMSCs encapsulated in hydrogels for 14 days (values are mean $\pm \mathrm{SD}(\mathrm{n}=3), \mathrm{P}<0.05(*)$ and $\mathrm{P}<0.01(* *)$, relative to G1).

(A)

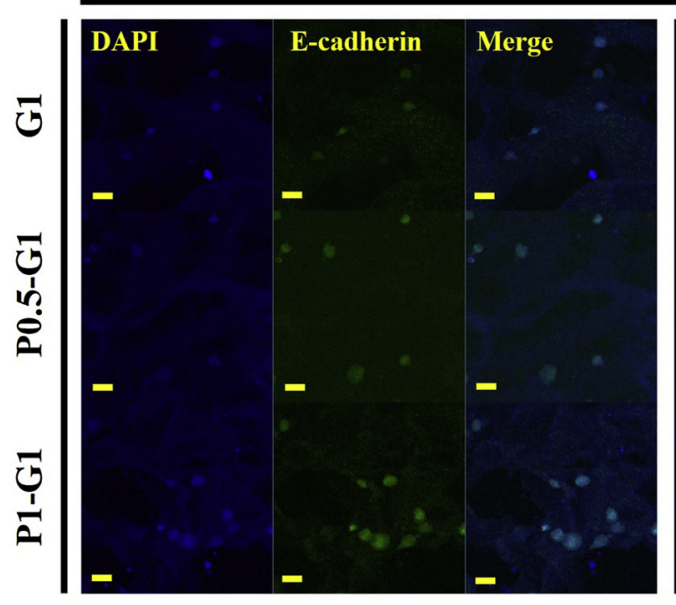

(B)

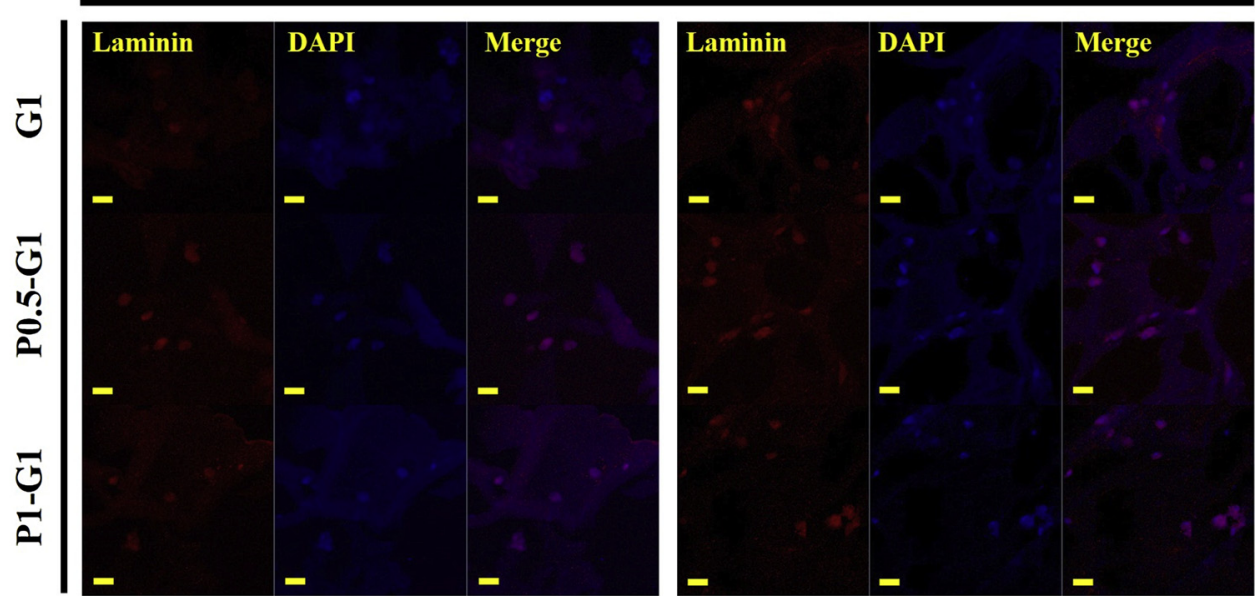

Fig. 7. Immunofluorecence staining of (A) E-cadherin (B) Laminin on 7 and 14 days of culture (scale bar $20 \mu \mathrm{m}$ ).
14 days

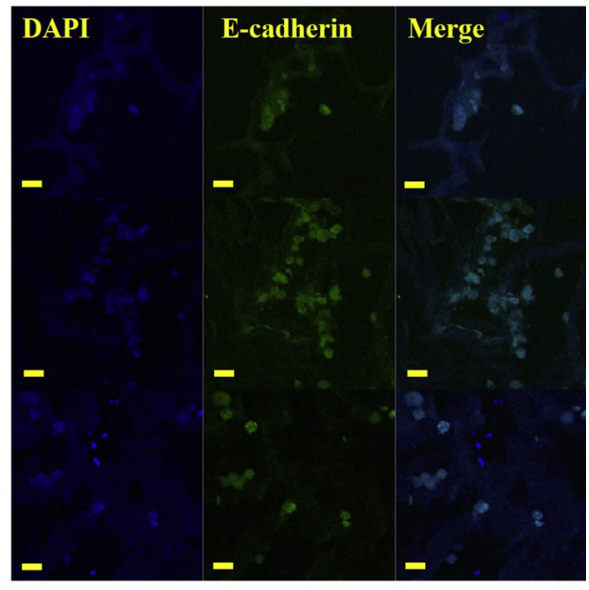

\section{4 days}



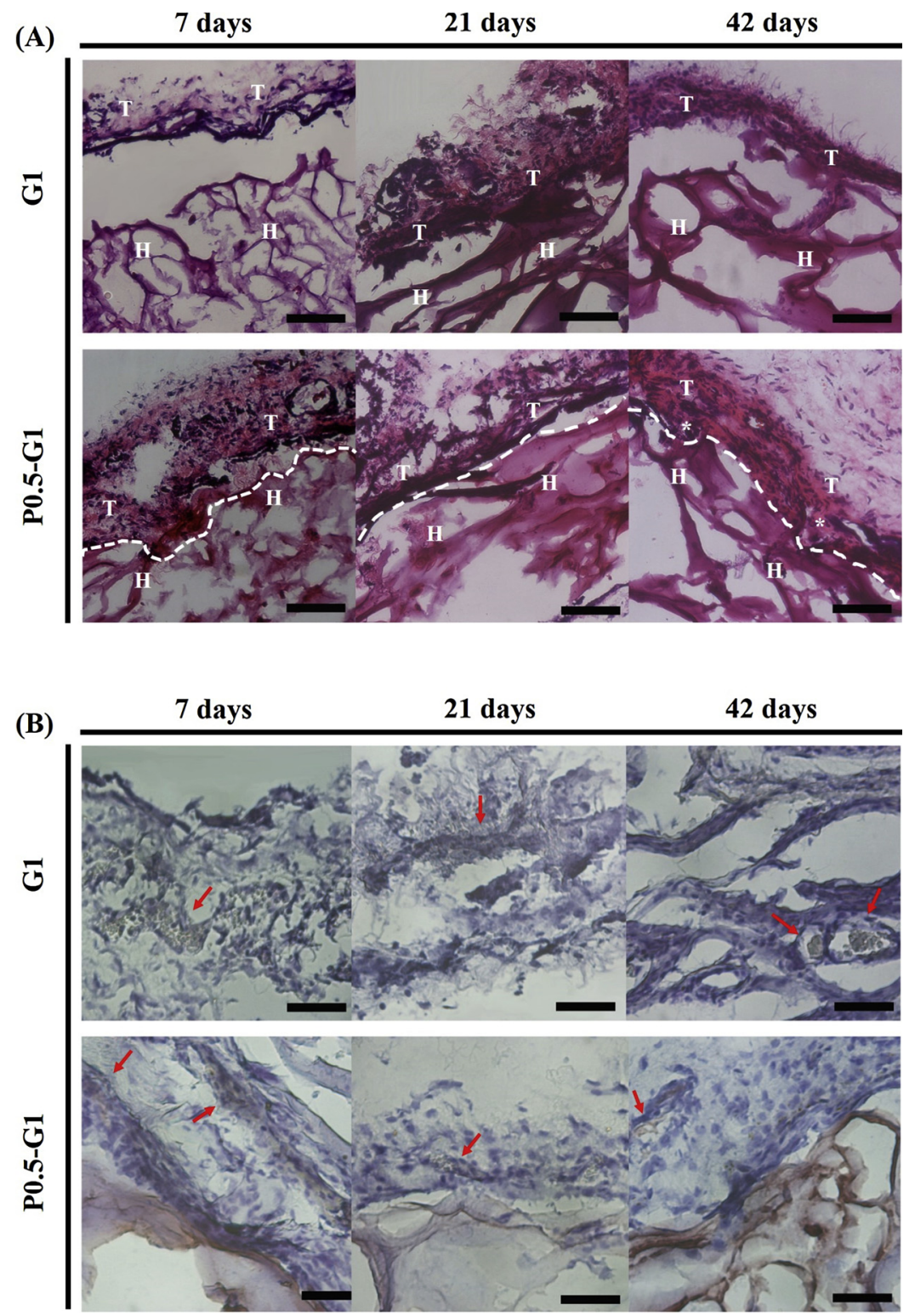

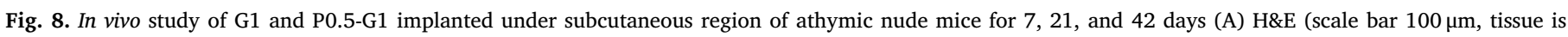

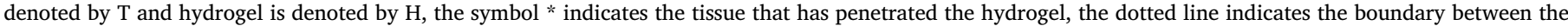

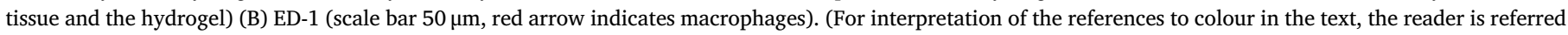
to the web version of this article.)

or ECM molecules can be applied to efficiently lead stem cells to a specific lineage. On the other hand, the mechanical properties of this hydrogel must be further improved, and long-term effects in vitro and in vivo are not yet known. In addition, this paper focuses only on osteogenesis, and the differentiation of MSCs to other lineage is not yet clear. Therefore, the future goal of this material is enhancing mechanical properties and directing the differentiation of mesenchymal stem cells by using growth factor-loaded PoH/GG hydrogels for various tissue engineering.

\section{Conclusion}

A double network hydrogel composed of gellan gum (GG) hydrogel and poloxamer-heparin $(\mathrm{PoH})$ was proposed as a matrix platform for stem cell cultivation. The composite of these two materials surmounted the microenvironment and gelation temperature of GG hydrogel and brittleness of PoH hydrogel. The aqueous solution of PoH/GG DNH presented a sol-gel transition around $\sim 36^{\circ} \mathrm{C}$. This indicates that the
PoH/GG DNH can be applied to thermosensitive injectable therapy for biomedical applications. The mechanical properties and morphology of hydrogels were stable. Moreover, the DNH system provided an excellent environment for cell adhesion and growth. Cell viability and proliferation were strongly affected by the composite of both hydrogels. rBMSCs phenotype maintained highest in the specific amount of $\mathrm{PoH}$ and expressed highest cell-cell interaction protein and ECM protein. The in vivo results also displayed higher cell adhesion and infiltration and lower inflammatory response in PoH/GG DNH. Therefore, the PoH/ GG DNH is a prospective candidate as a cell carrier for stem cell applied to tissue engineering.

\section{Acknowledgements}

This research was supported by a grant of the Korea Health Technology R\&D Project through the Korea Health Industry Development Institute (KHIDI), funded by the Ministry of Health \& Welfare, Republic of Korea (grant number: HI15C2996) and a grant of 
the Korea Health Technology R\&D Project through KHIDI (HI15C2996).

\section{Appendix A. Supplementary data}

Supplementary material related to this article can be found, in the online version, at doi:https://doi.org/10.1016/j.colsurfb.2019.06.041.

\section{References}

[1] R.S. Tuan, G. Boland, R. Tuli, Arthritis Res. Ther. 5 (2003) 32.

[2] D. Howard, L.D. Buttery, K.M. Shakesheff, S.J. Roberts, J. Anat. 213 (2008) 66.

[3] A.W. Lund, B. Yener, J.P. Stegemann, G.E. Plopper, Tissue Eng. Part B: Rev. 15 (2009) 371.

[4] J. Oliveira, L. Gardel, T. Rada, L. Martins, M.E. Gomes, R.L. Reis, J. Orthop. Res. 28 (2010) 1193.

[5] J. Zhu, R.E. Marchant, Expert Rev. Med. Dev. 8 (2011) 607.

[6] G.D. Nicodemus, S.J. Bryant, Tissue Eng. Part B: Rev. 14 (2008) 149.

[7] M.P. Lutolf, J.A. Hubbell, Nat. Biotechnol. 23 (2005) 47.

[8] H. Tan, C.M. Ramirez, N. Miljkovic, H. Li, J.P. Rubin, K.G. Marra, Biomaterials 30 (2009) 6844.

[9] Y. Gong, C. Wang, R.C. Lai, K. Su, F. Zhang, D. Wang, J. Mater. Chem. 19 (2009) 1968.

[10] A.H. Bacelar, J. Silva-Correia, J.M. Oliveira, R.L. Reis, J. Mater. Chem. B 4 (2016) 6164.

[11] J.T. Oliveira, L. Martins, R. Picciochi, P.B. Malafaya, R.A. Sousa, N.M. Neves, J.F. Mano, R.L. Reis, J. Biomed. Mater. Res. Part A 93 (2010) 852.

[12] D.F. Coutinho, S.V. Sant, H. Shin, J.T. Oliveira, M.E. Gomes, N.M. Neves, A. Khademhosseini, R.L. Reis, Biomaterials 31 (2010) 7494.

[13] C.J. Ferris, K.J. Gilmore, G.G. Wallace, Soft Matter 9 (2013) 3705.

[14] H. Lee, S. Fisher, M.S. Kallos, C.J. Hunter, J. Biomed. Mater. Res. B: Appl. Biomater. 2 (2011) 238

[15] M. Ahuja, S. Singh, A. Kumar, Int. J. Biol. Macromol. 53 (2013) 114.

[16] S. Yadav, M. Ahuja, A. Kumar, H. Kaur, Carbohydr. Polym. 99 (2014) 601.

[17] A. Gantar, L.P. Da Silva, J.M. Oliveira, A.P. Marques, V.M. Correlo, S. Novak, R.L. Reis, Mater. Sci. Eng. C 43 (2014) 27.

[18] R. Lozano, L. Stevens, B.C. Thompson, K.J. Gilmore, R. Gorkin, E.M. Stewart, M. Romero-Ortega, G.G. Wallace, Biomaterials 67 (2015) 264.

[19] M.B. Oliveira, C.A. Custódio, L. Gasperini, R.L. Reis, J.F. Mano, Acta Biomater. 41 (2016) 119.

[20] D. Bellini, C. Cencetti, J. Meraner, D. Stoppoloni, A.S. D’Abusco, P. Matricardi, Eur. Polym. J. 72 (2015) 642.

[21] S. Pacelli, P. Paolicelli, M. Avitabile, G. Varani, L. Di Muzio, S. Cesa, J. Tirillò, C. Bartuli, M. Nardoni, S. Petralito, et al., Eur. Polym. J. 104 (2018) 184.

[22] S. Pacelli, P. Paolicelli, F. Pepi, S. Garzoli, A. Polini, B. Tita, A. Vitalone, M.A. Casadei, J. Polym. Res. 21 (2014) 409.

[23] S. Pacelli, P. Paolicelli, I. Dreesen, S. Kobayashi, A. Vitalone, M.A. Casadei, Int. J. Biol. Macromol. 72 (2015) 1335

[24] V.H.M. Mouser, F.P.W. Melchels, J. Visser, W.J.A. Dhert, D. Gawlitta, J. Malda, Biofabrication 8 (2016).

[25] H. Shin, B.D. Olsen, A. Khademhosseini, Biomaterials 33 (2012) 3143.

[26] A. Nakayama, A. Kakugo, J.P. Gong, Y. Osada, M. Takai, T. Erata, S. Kawano, Adv. Funct. Mater. 14 (2004)

[27] W. Kubo, S. Miyazaki, D. Attwood, Int. J. Pharm. 10 (2003) 977.

[28] Y. Tang, J. Sun, H. Fan, X. Zhang, Carbohydr. Polym. 88 (2012) 46.

[29] X. Xu, Y. Shen, W. Wang, C. Sun, C. Li, Y. Xiong, J. Tu, Eur. J. Pharm. Biopharm. 88 (2014) 998

[30] L. Ci, Z. Huang, Y. Liu, Z. Liu, G. Wei, W. Lu, Acta Pharm. Sin. B 7 (2017) 593.

[31] G. Niu, F. Du, L. Song, H. Zhang, J. Yang, H. Cao, Y. Zheng, Z. Yang, G. Wang, H. Yang, et al., J. Control. Release 138 (2009) 49.

[32] M. Radivojša, I. Grabnar, P.A. Grabnar, Eur. J. Pharm. Sci. 50 (2013) 93.

[33] Y.Z. Zhao, H.F. Lv, C.T. Lu, L.J. Chen, M. Lin, M. Zhang, X. Jiang, X.T. Shen, R.R. Jin, J. Cai, et al., PLoS One 8 (2013).

[34] A.V. Vashi, E. Keramidaris, K.M. Abberton, W.A. Morrison, J.L. Wilson,
A.J. O'Connor, J.J. Cooper-White, E.W. Thomson, Biomaterials 29 (2008) 573.

[35] I.M.A. Diniz, C. Chen, X. Xu, S. Ansari, H.H. Zadeh, M.M. Marques, S. Shi, A. Moshaverinia, J. Mater. Sci. Mater. Med. 26 (2015) 153.

[36] E. Gioffredi, M. Boffito, S. Calzone, S.M. Giannitelli, A. Rainer, M. Trombetta, P. Mozetic, V. Chiono, Procedia CIRP 49 (2016) 125.

[37] Y.Z. Zhao, X. Jiang, J. Xiao, Q. Lin, W.Z. Yu, F.R. Tian, K.L. Mao, W. Yang, H.L. Wong, C.T. Lu, Acta Biomater. 29 (2016) 71.

[38] Y.Z. Zhao, H.F. Lv, C.T. Lu, L.J. Chen, M. Lin, M. Zhang, X. Jiang, X.T. Shen, R.R. Jin, J. Cai, et al., PLoS One 8 (2013) 1.

[39] J. Wu, J. Zhu, C. He, Z. Xiao, J. Ye, Y. Li, A. Chen, H. Zhang, X. Li, L. Lin, et al., ACS Appl. Mater. Interfaces 8 (2016) 18710.

[40] H.L. Xu, F.R. Tian, C.T. Lu, J. Xu, Z.L. Fan, J.J. Yang, P.P. Chen, Y.D. Huang, J. Xiao, Y.Z. Zhao, Sci. Rep. 6 (2016) 1.

[41] Q. Wang, Y. He, Y. Zhao, H. Xie, Q. Lin, Z. He, X. Wang, J. Li, H. Zhang, C. Wang, et al., ACS Appl. Mater. Interfaces 9 (2017) 6725.

[42] H.L. Xu, J. Xu, B.X. Shen, S.S. Zhang, B.H. Jin, Q.Y. Zhu, D.L. ZhuGe, X.Q. Wu, J. Xiao, Y.Z. Zhao, ACS Appl. Mater. Interfaces 9 (2017) 29580.

[43] L. Liao, B. Shi, H. Chang, X. Su, L. Zhang, C. Bi, Y. Shuai, X. Du, Z. Deng, Y. Jin, Theranostics 7 (2017) 106.

[44] M. Kim, Y.H. Kim, G. Tae, Acta Biomater. 9 (2013) 7833.

[45] M. Kumar, S.K. Nandi, D.L. Kaplan, B.B. Mandal, ACS Biomater. Sci. Eng. 3 (2017) 2443.

[46] X. Zhao, Q. Lang, L. Yildirimer, Z.Y. Lin, W. Cui, N. Annabi, K.W. Ng, M.R. Dokmeci, A.M. Ghaemmaghami, A. Khademhosseini, Adv. Healthc. Mater. 5 (2016) 108.

[47] H. Park, X. Guo, J.S. Temenoff, Y. Tabata, A.I. Caplan, F.K. Kasper, A.G. Mikos, Biomacromolecules 10 (2009) 541.

[48] J. Han, Z. Zhou, R. Yin, D. Yang, J. Nie, Int. J. Biol. Macromol. 49 (2010) 199.

[49] M.B. Browning, S.N. Cereceres, P.T. Luong, E.M. Cosgriff-Hernandez, J. Biomed. Mater. Res. Part A 102 (2014) 4244.

[50] S.P. Zustiak, J.B. Leach, Biomacromolecules 11 (2010) 1348.

[51] Y. Deng, J. Ren, G. Chen, G. Li, X. Wu, G. Wang, G. Gu, J. Li, Sci. Rep. 7 (2017) 1.

[52] M. Maisani, D. Pezzoli, O. Chassande, D. Mantovani, J. Tissue Eng. 8 (2017) 204173141771207

[53] Y.-M. Kook, Y. Jeong, K. Lee, W.-G. Koh, J. Tissue Eng. 8 (2017) 204173141772464

[54] S.L. Vega, M.Y. Kwon, J.A. Burdick, Eur. Cells Mater. 33 (2017) 59.

[55] M.W. Tibbitt, K.S. Anseth, Biotechnol. Bioeng. 103 (2009) 655.

[56] J. Kalisky, J. Raso, C. Rigothier, M. Rï $i 1 \frac{1}{2} m y$, R. Siadous, R. Bareille, J.C. Fricain, J. Amedï ¿ $1 / 2 \mathrm{e}-$ Vilamitjana, H. Oliveira, R. Devillard, Sci. Rep. 6 (2016) 1.

[57] P. Matricardi, C. Cencetti, R. Ria, F. Alhaique, T. Coviello, Molecules 14 (2009) 3376.

[58] B. Kumar, S. Kulanthaivel, A. Mondal, S. Mishra, B. Banerjee, A. Bhaumik, I. Banerjee, S. Giri, Colloids Surf. B: Biointerfaces 150 (2017) 352.

[59] L. Wang, C. Lu, H. Liu, S. Lin, K. Nan, H. Chen, L. Li, RSC Adv. 6 (2016) 1194.

[60] C.M. Murphy, M.G. Haugh, F.J. O’Brien, Biomaterials 31 (2010) 461.

[61] F.J. O’Brien, B.A. Harley, I.V. Yannas, L.J. Gibson, Biomaterials 26 (2005) 433.

[62] K.M. Park, S.Y. Lee, Y.K. Joung, J.S. Na, M.C. Lee, K.D. Park, Acta Biomater. 5 (2009) 1956.

[63] I. Caron, F. Rossi, S. Papa, R. Aloe, M. Sculco, E. Mauri, A. Sacchetti, E. Erba, N. Panini, V. Parazzi, et al., Biomaterials 75 (2016) 135.

[64] F. Gentile, L. Tirinato, E. Battista, F. Causa, C. Liberale, E.M. di Fabrizio, P. Decuzzi, Biomaterials 31 (2010) 7205.

[65] A.J. Engler, S. Sen, H.L. Sweeney, D.E. Discher, Cell 126 (2006) 677.

[66] S. Gobaa, S. Hoehnel, M. Roccio, A. Negro, S. Kobel, M.P. Lutolf, Nat. Methods 8 (2011) 949.

[67] R.S. Ashton, A. Banerjee, S. Punyani, D.V. Schaffer, R.S. Kane, Biomaterials 28 (2007) 5518 .

[68] A. Van der Flier, A. Sonnenberg, Cell Tissue Res. 305 (2001) 285.

[69] P. Friedl, Y. Hegerfeldt, M. Tusch, Int. J. Dev. Biol. 48 (2004) 441.

[70] P. Roca-Cusachs, N.C. Gauthier, A. Del Rio, M.P. Sheetz, Proc. Natl. Acad. Sci. U. S. A. 106 (2009) 16245.

[71] J. Liao, T. Tian, S. Shi, X. Xie, Q. Ma, G. Li, Y. Lin, Bone Res. 5 (2017) 17018.

[72] N. Annabi, D. Rana, E. Shirzaei Sani, R. Portillo-Lara, J.L. Gifford, M.M. Fares, S.M. Mithieux, A.S. Weiss, Biomaterials 139 (2017) 229. 